\title{
The application research about theory model of mobile payment
}

\author{
Chu XiaoQing* \\ Dalian Ocean university, Dalian Liaoning,116300,China \\ Wafangdian Dalian,116300,China \\ anfxwmy@163.com
}

\begin{abstract}
China is the country with the largest number of mobile terminals, and has a great market development potential. But compared with some developed countries, our mobile payment is behind a lot, and now our mobile payment has not been recognized by all consumer groups. There is an important hot issue in this paper about the mobile payment that is how to strengthen consumers continue to use mobile payment, and applied payment theory model to mobile payment. It also has effect of payment theory model on mobile payments is analyzed in detail and has further study.
\end{abstract}

Keywords: Mobile payment. Theory model. Big data.

\section{Introduction}

Mobile payment is a new and innovative way of payment, and because it has a characteristics of a safe, convenient and fast which makes mobile payment accepted and loved by more and more people. The statistics show that in 2014 China's rapid development of mobile payments grew by $389.5 \%$ year on year, the total transaction size reached 5 trillion and 884 billion 270 million yuan [1]. By the end of last year, The number of consumers to pay for the use of mobile payments was 304 million, an increase of $17 \%$ reached 44 million 220 thousand people. With the popularity of phones, people who use mobile phones to pay the number of consumers is increasing .And in 2014 year ,that increased by $73.2 \%$ over 2013 year[2]. At the same time, the proportion of consumers using online payment has also been greatly improved. The ratio of using online payment is up to $16.9 \%$ [3]. 2015 will be the key year for the development of mobile payment in China. The first is the establishment of the national standard of China Union Pay $13.56 \mathrm{MHz}$, And to lay a solid foundation for the future development of mobile payment industry in China, secondly, mobile payment participants on the industry's efforts to put a lot, and providing guarantee for the development of mobile payment. But how to strengthen the consumer continues to use mobile payment,that is currently facing new problems.

\section{The establishment and analysis of the theoretical model of mobile payment}

\subsection{The establishment of the theoretical model of mobile payment}

Along with the fast development of the financial industry, the Internet, the importance of entertainment applications in consumer work life more and more low, the opposite is represented by the online shopping, online payment business class application development is rapid, alarming number of users, business class permeability is higher and higher in the application in Internet users. And Venkatesh and Davis (2003) by the user to accept multiple integration of classical theory in the field of neat, after the establishment of a complete integrated technology acceptance model (Unified Theory of Acceptance and Use of Technology, UTAUT) [4].As shown in figure 1: 


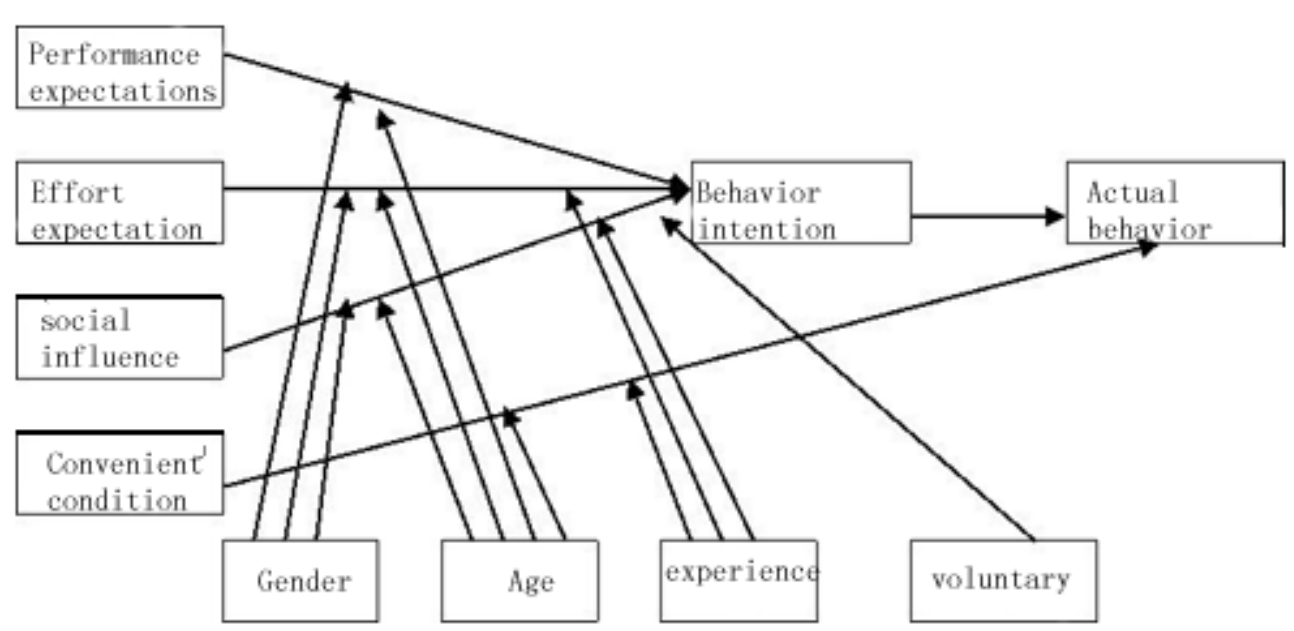

Figure 1 integration of technology acceptance model

Analysis of characteristics of the model, the author believes that the model can be applied in the field of mobile payment, for example, performance expectations, can be considered as consumers buy a service or product after the work performance of ascension, individual effort is expected to perceive a particular level of friendly interface and information technology products, ease to use, perceived ease of use, complexity, and to evaluate whether easy to use efforts can be expected. Social impact refers to gender, age, experience, and voluntary are likely to impact on the social impact and the relationship between the behavior intentions[5]. But these effects at the beginning of the new product will generate, with the increase of using time, the effect will gradually decline. Subjective norms, image, etc can explain to social factors. And convenience is the individual perceives the existing condition and the technology to support the use of a particular information technology products the degree of perceived behavior control, contributing to conditions and consistency this construct dimensions constitute a convenient conditions, such as at the same time the conveniences with age and experience will influence the relationship between the actual behavior.

\subsection{The analysis of the application of Technology Acceptance Model in the field of mobile payment}

\subsubsection{The use of context has a very positive impact on the continued using}

From the operator's point of view, to further enrich the mobile payment's payment environment, in people's daily life consumption environment to support mobile payment services, for example, in the supermarket, ticket office and some study office, by making special payment environment, to promote the use and development of mobile payment[6]. The Shanghai Pudong Development Bank and China Mobile have jointly launched a NFC customized mobile phone, through wireless communication technology, consumers can consumer credit card using a mobile phone, but this custom has not been recognized by everyone, one reason is the lack of publicity, it is not enough understanding of the mobile phone and the near field payment, on the other hand, because the hardware infrastructure is limited, for its consumer use place is too small, the last reason is said before NFC payment standards are not unified, if the mobile payment service providers (banks, operators and third A third-party payment platform) and government departments can work together to strengthen the construction of infrastructure and the establishment of a unified payment standard, 
believe that the use of mobile payment scenarios will be more extensive, the mobile payment in the future road will be more wide.

2.2.2 The impact of social impact on the consumer's continued use of a significant positive impact

For the no experience consumers, positive evaluation about mobile payments have passed to him through a network or his friends, then have a good impression on the products of mobile payment services before use and will increase the use of mobile payment and probability, using mobile payment obligations, will enhance its evaluation mobile payment business, and actively spread positive information to the people around. In view of this phenomenon, the mobile payment operators should be increased for consumers exchange platform, consumers can use their feedback to manufacturers and other consumers, in this way can further enhance the social impact of the continued use of influence on pay mobile, in order to expand the number of users.

2.2.3 Perceived risk has no effect on the degree of satisfaction but with the negative impact of continued use intention

In the study about the continuous use intention, experts and scholars have found that perceived risk has significant negative impact on continuance intention, the biggest risk in mobile payment process from the security industry. Service providers should work together to strengthen the consumer's mobile payment, payment security, the current consumer personal information leakage extremely serious, to protect the user's personal information security is very important. Just recently, the use of online banking and Commercial Bank posing steal money cases. The third party payment platform, operators and banks should strengthen the technology and capital investment, the establishment of the ecological system of payment security, you can learn from the foreign advanced company reference.

\section{Conclusions and Outlook}

Summary of the above analysis, we can see that with the rapid development of mobile information technology, changed consumer payment, mobile payment to customers fast, convenient service at the same time also led to the overall development of mobile payment industry. China is the largest number of national mobile terminal, has great market potential. But compared with some developed countries, we still lag behind a lot of mobile payments. Mobile payment is not accepted by all consumer groups. This paper focuses on the application of acceptance model of mobile payment -influence of major groups of young consumers continuance intention factors, explore influence factors enhance consumers' mobile payment and through intention. The government is gradually perfect the laws and regulations of the mobile payment industry, mobile payment industry to strengthen supervision. The government, operators, silver And the third party payment enterprises to establish safety norms of industry chain through cooperation, reduce the security risks of mobile payment, mobile payment industry will get a higher level.

\section{Acknowledgement}

The 13th Five-year Plan in The Liaoning Education Science in Liaoning Province with 2016 annual project "Research and Practice on the way and method of network payment under big database" 


\section{References}

[1]Li qi. The mobile payment users of the Chinese culture under the intention and behavior analysis, based on the integrated information acceptance model [J]. Journal of social scientists. (136) : 2008-53 50 .

[2] Li qi. Mobile payment users use intention and behavior model and empirical study [J]. Journal of statistics and information BBS. 2009 (24) : 72-77.

[3] Hua-ping Chen. Users of mobile payment and use behavior study [J]. Journal of management science. 2006 (6) : 48-55.

[4] Shou-peng wang. Based on the UTAUT mobile payment will influence factors of the continuous use research [D]. The northeast university of finance and economics, 2015.

[5]Lin G C S, Yi F. Urbanization of capital or capitalization on urban land? Land development and local public finance in urbanizing China[J]. Urban Geography, 2011, 32(1): 50-79.

[6] Robalino J A. Land conservation policies and income distribution: who bears the burden of our environmental efforts?[J]. Environment and Development Economics, 2007, 12(4): 521-533. 